\title{
De Nederlandse strafrechter en culturele delicten
}

\author{
H.D. Wolswijk *
}

\section{Inleiding}

De Nederlandse strafrechter krijgt nogal eens te maken met zogenaamde 'culturele delicten'. Deze delicten worden wel omschreven als "gedragingen, strafbaar volgens ons strafrecht, maar toelaatbaar volgens intern recht van de sociale groep - meestal een migrantengroep - waartoe de justitiabele behoort." In onze samenleving gaat het vooral om groepen die (oorspronkelijk) afkomstig zijn uit Turkije en uit Afrikaanse, Latijns-Amerikaanse en Aziatische landen. Bekende voorbeelden zijn gevallen van eerwraak (levensberovingen of geweldgebruik voortvloeiend uit gekrenkte persoonlijke of familie-eer), meisjesbesnijdenis en bijzondere begrafenisrituelen. In deze bijdrage wordt bezien in hoeverre de 'culturele dader' zich (succesvol) kan verweren met een beroep op zijn cultuur. ${ }^{2}$ Centraal staat de vraag naar

* Hein Wolswijk is universitair hoofddocent strafrecht aan de Rijksuniversiteit Groningen.

1 F. Strijbosch, Culturele delicten in de Molukse gemeenschap, NJB 1991, p. 666. Vgl. ook de iets ruimere omschrijving van 't Hart in zijn noot onder HR 26 mei 1992, NJ 1992, 568.

2 Over het onderwerp (of deelonderwerpen) is al veel geschreven. Een greep uit de literatuur (in chronologische volgorde): R.H. Wormhoudt, Culturele achtergronden: strafuitsluitingsgronden?, Proces 1986, p. 329-336; W. Huisman, Culturele delicten, Proces 1995, p. 80-88; S. Bloemink, Cultureel verweer, in: G. Anders e.a. (red.), De onvermijdelijkheid van rechtspluralisme, Nijmegen: Ars Aequi Libri 1998, p. 53-68; C.W. Maris van Sandelingenambacht, Wie is de vader, wie is de dader?, NJB 2001, p. 1708-1712; H.C. Wiersinga, Nuance in benadering, culturele factoren in het strafproces, Den Haag: Boom Juridische uitgevers 2002; M. Bovens, Cultuur als verweer, in: F. Bovenkerk e.a. (red.), Multiculturaliteit in de strafrechtspleging, Den Haag: Boom Juridische uitgevers 2003, p. 137-150; M.G.J. Post, Detentie en culturele diversiteit, Den Haag: Boom Juridische uitgevers 2005; M. Siesling, Multiculturaliteit en verdediging in strafzaken, Den Haag: Boom Juridische uitgevers 2006; J.M. ten Voorde, Cultuur als verweer, Een grondslagentheoretische studie naar de ruimte en grenzen van culturele diversiteit in enige leerstukken van materieel strafrecht, Nijmegen: Wolf Legal Publishers 2007; 
de rol van cultuur bij de strafuitsluitingsgronden, ${ }^{3}$ in het bijzonder de psychische overmacht (paragraaf 3), en bij de straftoemeting (paragraaf 4). Eerst, in paragraaf 2, worden echter enkele opmerkingen gemaakt over het begrip cultuur.

\section{Cultuur}

Over de vraag wat cultuur 'is' of 'doet' bestaan vele, zeer uiteenlopende opvattingen. ${ }^{4}$ Aan het ene eind van het spectrum staat het essentialistische (ook wel: culturalistische) cultuurbegrip. In de essentialistische visie is cultuur een vaststaand gegeven, waaraan een dwingende kracht wordt toegekend en waaraan men zich niet kan onttrekken. Cultuur is een 'ding' dat onafhankelijk is van veranderende omstandigheden. Eenvoudig gezegd: mensen en hun gedragingen zijn slechts een product van cultuur ('my culture made me do it'). Aan het andere eind van het spectrum van opvattingen staat het constructivistische standpunt. In die opvatting is cultuur juist het resultaat van het proces van interactie waarmee mensen betekenis geven aan hun wereld. Cultuur is niet een onveranderlijk gegeven, maar wordt door mensen zelf - meer of minder bewust - gemaakt. Cultuur is dan een product van de mens. Tegenwoordig wordt veelal een tussenpositie verdedigd: het gematigd constructivisme. Enerzijds is cultuur een product van menselijk (samen)handelen, anderzijds kan cultuur ook niet zo maar worden 'afgelegd' en stuurt cultuur iemands handelen.

Deze onduidelijkheid over het begrip cultuur levert in die zin een probleem op, dat de gebruikte definitie vanzelfsprekend (mede)bepalend is voor het antwoord op de vraag naar de invloed van cultuur op het strafrecht. Voor de hand ligt, dat de essentialistische visie meer juridische relevantie heeft - in ieder geval voor zover het gaat om de invloed ervan op iemands

H.D. Wolswijk, Multiculturaliteit en Nederlands strafrecht, Vereniging voor de vergelijkende studie van het recht van België en Nederland; Samenloop van grondrechten in verschillende rechtsstelsels, multiculturaliteit in het strafrecht \& schuldsanering en collectieve schuldenregeling; Preadviezen 2008, Den Haag: Boom Juridische Uitgevers 2008.

3 Overigens speelt cultuur ook op het niveau van de delictsbestanddelen een rol (is er wel een delict gepleegd?) Denk bijvoorbeeld aan de vraag of culturele (minderheids)opvattingen relevant zijn voor de betekenis van het bestanddeel 'ontuchtig' (o.m. in art. $246 \mathrm{Sr}$ ). Zie hierover Wolswijk (noot 2), p. 203 e.v.

4 Zie hierover S. Tempelman, Duiken in het duister: een gematigd constructivistische benadering van culturele identiteit, Migrantenstudies 1999, p. 70-82. 
handelen - dan de (gematigd) constructivistische. In een extreem essentialistische variant is de invloed van cultuur op iemands handelen misschien wel zodanig dat van enig wilselement in het geheel geen sprake is en daarmee evenmin van een strafrechtelijk relevante gedraging (vergelijkbaar met iemand die handelt onder hypnose). In dit cultuurdebat wordt hier geen stelling genomen. Dat betekent dat het in het onderstaande steeds gaat om de mogelijke invloed van cultuur.

\section{Strafuitsluitingsgronden}

Cultuur of culturele invloed is geen zelfstandige strafuitsluitingsgrond. De culturele factor moet binnen het bestaande stelsel van strafuitsluitingsgronden 'verwerkt' worden. In de praktijk zijn in dit verband twee strafuitsluitingsgronden van belang: ontoerekenbaarheid en - vooral - psychische overmacht.

\subsection{Ontoerekenbaarheid}

Een strafbaar feit kan aan de dader niet toerekenbaar zijn wegens de gebrekkige ontwikkeling of ziekelijke stoornis van zijn geestvermogens (art. $39 \mathrm{Sr}$ ). Daarvan zal doorgaans bij de culturele dader geen sprake zijn. Bloemink heeft in dit verband terecht opgemerkt dat het ook "zeer onwenselijk [is] om gedragingen die in een bepaalde cultuur meer dan in de westerse cultuur worden getolereerd en begrepen (...) als gedragingen te beschouwen die uit een geestelijke afwijking voortkomen. In veel gevallen wordt het stempel 'gek' als nog meer stigmatiserend ervaren dan het stempel 'crimineel'." Wel komt het voor dat het feit slechts in verminderde mate kan worden toegerekend vanwege een ziekelijke stoornis en dat die stoornis, zoals een aanpassingsstoornis in de emoties, het gevolg is van 'acculturatieproblematiek' ${ }^{6}$ Dan is art. 39 Sr niet van toepassing; de dader blijft strafbaar, maar de verminderde toerekenbaarheid zal doorwerken in de strafmaat. (Volledige) ontoerekenbaarheid komt eerder in beeld bij daders die in een trance of een staat van bezetenheid een strafbaar feit plegen. Aan een dergelijke toestand kunnen culturele fenomenen als winti of voodoo ten grondslag liggen. ${ }^{7}$ 


\section{2 (Psychische) overmacht}

De dader is niet strafbaar indien hij 'een feit begaat waartoe hij door overmacht is gedrongen' (art. $40 \mathrm{Sr}$ ). De dogmatiek onderscheidt tussen de (rechtvaardigende) overmacht-noodtoestand en de (schulduitsluitende) psychische overmacht. Overmacht-noodtoestand speelt in de rechtspraak over culturele delicten geen rol van betekenis en blijft hier buiten beschouwing. Bij psychische overmacht wordt op de dader een zodanige, van buitenaf komende druk uitgeoefend dat zijn wilsvrijheid wordt aangetast, terwijl weerstand bieden aan die druk redelijkerwijs niet gevergd kan worden. ${ }^{8}$ Door de druk van de omstandigheden kan het wederrechtelijke gedrag de dader niet verweten kan worden. De beoordeling van de psychische overmacht vergt zowel een psychologische toetsing (kón de dader weerstand bieden), als een normatieve (behóórde hij weerstand te bieden).

In de rechtspraak over culturele delicten wordt regelmatig een beroep gedaan op psychische overmacht. Dat laat zich eenvoudig verklaren, ervan uitgaande dat iemands cultuur of culturele achtergrond zijn vrijheid van handelen meer of minder kan beïnvloeden. De - algemeen gezegd culturele omgeving zou dan de drang vormen die de wilsvrijheid van de dader beperkt, en maken dat anders handelen redelijkerwijs niet gevergd zou kunnen worden. Om dat te beoordelen zal die culturele omgeving echter 'ontleed' moeten worden. Dan rijst ook al snel de vraag in hoeverre wel van een werkelijk cultureel verweer sprake is. Bestond de drang uit (alleen) het eigen culturele normenpatroon? Oefende het enkele gegeven dat, bijvoorbeeld, de familie-eer slechts beschermd kon worden door de strafbare gedraging te verrichten, een drang uit op de dader? Of werd de dader (eventueel óók) onder druk gezet door familieleden? En bestond die druk uit het confronteren met het culturele verwachtingspatroon, uit het dreigen met uitstoting uit de groep of uit 'gewoon' dreigen met geweld? Zeker het laatste geval laat zien dat bij een door anderen uitgeoefende druk al snel factoren kunnen meespelen die niet cultuurbepaald zijn, althans niet bepaald door de cultuur waartoe de dader behoort. Dat geldt overigens ook indien die druk van anderen er niet is. Overspel door de echtgenote of de wens tot echtscheiding kunnen ook bij de autochtone dader gevoelens van jaloezie en wraak oproepen en hem aanzetten tot strafbare gedragingen. 
Hoewel vaak aangevoerd, is het beroep op psychische overmacht tot dusver in de rechtspraak altijd afgewezen. ${ }^{9}$ Vrijwel steeds betreft het levens- of geweldsdelicten begaan uit eerwraak, waarbij de bescherming van de eigen of familie-eer in het geding is. Dat aan het delict een eerwraakmotief ten grondslag ligt, zegt in dit verband nog niets, in het bijzonder niet dat de wilsvrijheid van de dader is aangetast. Integendeel, de dader kan uit volle overtuiging hebben gehandeld (zie ook hierna paragraaf 4). Terecht stelde de Rechtbank Den Bosch: "De vraag is niet of de aanwezigheid van een eerwraak-motief moet leiden tot een zwaardere of lichtere straf dan wanneer een dergelijk, cultureel bepaald motief niet aanwezig is, maar of dat eerwraak-motief en de daarmee verband houdende factoren (...) deze verdachte zo onder druk hebben gezet dat hij daaraan redelijkerwijs niet weerstand had kunnen bieden [cursivering HDW]." ${ }^{10}$ Hoewel de rechter doorgaans erkent dat de dader onder een zekere druk heeft gestaan - van familie en/of culturele achtergrond -, wordt uiteindelijk toch onaannemelijk geacht dat de dader in redelijkheid niet in staat is geweest zich van de strafbare gedraging te onthouden.

Van de psychologische toetsing is in de motivering van uitspraken vaak weinig terug te vinden, hetgeen er ongetwijfeld mee te maken heeft dat de rechter hier minder houvast heeft, althans dat zo voelt. Bij deze toetsing rijst immers de lastige vraag welke invloed cultuur op iemands handelen kan hebben (zie paragraaf 2). Indien echter een deskundige is ingeschakeld, ontkomt de rechter niet aan een standpuntbepaling. Een voorbeeld is de uitspraak van de rechtbank Den Bosch in de Veghelse eerwraakzaak van een aantal jaren geleden. ${ }^{11}$ De rechtbank vond de stelling van de ingeroepen deskundige dat de verdachte "onder onhoudbare druk van zijn familie en van zijn omgeving is gekomen om de familie-eer te redden" onvoldoende onderbouwd: "De omstandigheid dat, zoals deze deskundige stelt, binnen de culturele context en de gezinscontext collectivistische waarden prevaleren boven individualistische belangen en dat in die constellatie het (westerse) begrip wilsvrijheid een illusie is, acht de rechtbank geen toereikende onderbouwing: enerzijds niet omdat niet valt in te zien dat prevalentie van collectivistische waarden geen enkele ruimte laat voor (individuele) wilsvrijheid, anderzijds niet omdat niet wordt duidelijk gemaakt waarom die druk vanuit

9 Zie o.m. HR 20 november 1979, NJ 1980, 129; Hof Leeuwarden 19 juni 2000, LJN AD8362; Hof Leeuwarden 5 november 2003, LJN AN7321.

10 Rechtbank 's-Hertogenbosch 13 februari 2001, LJN AA9954.

11 Rechtbank 's-Hertogenbosch 13 februari 2001, LJN AA9954. 
de collectivistische waarden zo zwaar was dat verdachte daaraan geen weerstond kon noch hoefde te bieden."

In de motivering van de verwerping van het beroep op psychische overmacht krijgt vooral de normatieve toets aandacht. Daarbij speelt vrijwel steeds de ernst van het gepleegde feit een grote rol: hoe ernstiger het gepleegde delict, des te eerder zal de rechter oordelen dat anders handelen redelijkerwijs gevergd kon worden. Daarnaast is aan de subsidiariteitseis vaak niet voldaan. De rechter gaat er dan van uit dat de eerkwestie - soms óók volgens de eigen cultuur - op andere, minder ingrijpende wijze had kunnen worden opgelost of dat de dader hulp had kunnen zoeken bij andere personen. ${ }^{12}$ Het is dus vooral de normatieve toetsing die aan een geslaagd beroep op psychische overmacht in de weg staat. Bij ernstige delicten wil de rechter er niet aan dat de invloed van de culturele omgeving op de wilsvrijheid zodanig kan zijn, dat het nalaten van de gedraging redelijkerwijs niet van de dader gevergd kon worden. ${ }^{13}$ Daarbij speelt wellicht ook het punt waarop Knigge, ${ }^{14}$ in navolging van Van Veen,${ }^{15}$ heeft gewezen, namelijk dat bij de aanvaarding van psychische overmacht een rechtspolitiek argument meespeelt. Dat wil zeggen: die aanvaarding hangt mede af van hetgeen de samenleving zich in dit opzicht kan veroorloven. Honorering van het beroep op de dwang die van de eigen cultuur uitgaat, "zou betekenen dat de (potentiële) slachtoffers van de gruweldaden waartoe die cultuur aanzet, geen adequate strafrechtelijke bescherming kan worden geboden. Aan de culturele dwang dient het strafrecht juist tegenwicht te bieden door een ernstig te nemen strafbedreiging."

Het gaat er uiteindelijk om wat redelijkerwijs van de dader is te vergen. Dat kan uiterst moeilijk te beoordelen zijn. De persoon van de dader is van belang en daarmee kan ook diens culturele achtergrond een rol spelen. Maar wat redelijk is wordt op zichzelf niet bepaald door de dader of diens cultuur. Een goed voorbeeld is het vonnis van de Rechtbank 's-Gravenhage in de zaak van het meisje Mehak. ${ }^{16}$ Een uit India afkomstige Hindoestaanse

12 Soms is de toepassing van de subsidiariteitstoets wel heel weinig overtuigend. Volgens Rechtbank Amsterdam 7 juli 2004, LJN AP8622, was gebleken dat de verdachte "wel degelijk alternatieven had, met name het alternatief om niet te doen wat hij heeft gedaan [curs. HDW]."

13 Vgl. ook B.F. Keulen, Het strafrecht en de overtuiging, in: Ontmoetingen, Voordrachtenreeks van het Lutje P.J.G., 2006, nr. 12, p. 24, 25.

14 Noot onder HR 14 oktober 2003, NJ 2005, 183.

15 Noot onder HR 17 september 1992, NJ 1993, 267.

16 Rechtbank's-Gravenhage 14 december 2007, LJN BC0775. 
vrouw wordt vervolgd wegens moord op haar (zeer jeugdige) dochter. Het meisje zou 'behekst' zijn en de moeder stond onder zware druk stond om daartegen iets 'te ondernemen'. Dat leidde tot verwaarlozing van het meisje en tot veelvuldig slaan, ook door anderen, met zwaar lichamelijk letsel en uiteindelijk de dood ten gevolg. Bij de bespreking van het beroep op overmacht komt de rechter tot de conclusie dat de moeder onvoldoende heeft gedaan om aan de druk het kind iets aan te doen te ontkomen en voegt daaraan toe: "De rechtbank is zich ervan bewust dat dit oordeel mede berust op een keuze voor het toepassen van Nederlandse maatstaven [curs. HDW], terwijl verdachte van Indiase afkomst is en ook in een overwegend Indiase setting leefde, hetgeen kennelijk een naar westerse maatstaven onbegrijpelijke lijdzaamheid meebrengt. Omdat de gebeurtenissen toch in Nederland hebben plaatsgevonden, kiest de rechtbank ervoor de norm die strekt tot bescherming van de gezondheid en het leven van een klein kind door de moeder boven het belang van de moeder bij voorkoming van sociale uitsluiting te stellen, en aldus die lijdzaamheid niet als voor verdachte onvermijdelijk te accepteren." De keuze voor het toepassen van 'Nederlandse maatstaven' - opgevat als: maastaven van de Nederlandse rechtsorde - is terecht. Het kan er in deze context niet om gaan wat de dader redelijk vindt. Dat betekent echter niet dat de persoon van de dader of diens achtergrond niet van belang is. De vraag is immers wat volgens de Nederlandse rechtsorde van deze dader, mede gelet op diens achtergrond, redelijkerwijs gevergd kan worden.

Met het voorgaande is niet gezegd dat een beroep op psychische overmacht bij ernstige feiten nooit kans van slagen heeft. Dat hangt af - uiteraard - van de omstandigheden van het geval. Zo kan de (jeugdige) leeftijd van de dader van belang zijn, evenals het feit dat de druk uit de culturele omgeving de vorm van dreigementen richting de toekomstige dader heeft aangenomen. ${ }^{17}$ Maar dan gaat het - zie reeds hiervoor - ook niet meer zozeer om culturele factoren die de druk vormen en de wilsvrijheid mogelijk aantasten. ${ }^{18}$ Dergelijke factoren kunnen immers in het algemeen een rol spelen bij een beroep op psychische overmacht. Met het voorgaande is overigens evenmin gezegd dat een beroep op psychische overmacht bij lichte vergrijpen eerder kans van

17 Vgl. ook F. Strijbosch, Eerwraak, onderzoek en strafrecht, NJB 2001, p. 889.

18 Vgl. Maris van Sandelingenambacht (noot 2), p. 1711. 
slagen heeft. Waarschijnlijk is in die gevallen de druk die op de dader is uitgeoefend ook minder groot.

\section{Straftoemeting}

Waar de invloed van cultuur niet leidt tot een strafuitsluitingsgrond, kan deze factor wel van belang zijn bij de straftoemeting. Het duidelijkst is dat wanneer het strafbare feit de dader slechts in verminderde mate kan worden toegerekend vanwege een ziekelijke stoornis die het gevolg is van 'acculturatieproblematiek' (paragraaf 3.1). Strafuitsluiting ex art. $39 \mathrm{Sr}$ is in dat geval niet aan de orde, maar de verminderde toerekenbaarheid werkt wel strafverlagend.

"De centrale vraag is of cultuur een reden kan zijn om een lichtere of juist een zwaardere straf op te leggen." ${ }^{19}$ Daarover lijkt nog grote onduidelijkheid te bestaan. ${ }^{20}$ Soms wordt in een zaak met een culturele achtergrond in de strafmotivering niets over die achtergrond gezegd. Soms ook wordt wel naar de culturele achtergrond verwezen, maar laat de rechter in het midden welke rol deze uiteindelijk speelt. ${ }^{21}$ De "centrale vraag" of cultuur strafverlagend of juist verhogend moet werken, kan echter niet in zijn algemeenheid beantwoord worden - en is zo bezien dus ook niet de juiste vraag. Zoals ook bij de psychische overmacht, dient daartoe eerst duidelijk te worden waaruit de culturele achtergrond in het concrete geval bestaat. Indien die bestaat in een op de dader uitgeoefende druk door de familie om het delict te plegen omdat de familie-eer hersteld moet worden, is dat een geheel andere achtergrond dan wanneer de dader uit volle (culturele) overtuiging het feit heeft begaan. Zeer terecht overwoog de Rechtbank 's-Hertogenbosch, die ook het beroep op psychische overmacht genuanceerd benaderde (paragraaf 3.2), "dat het niet gaat om de vraag of in zijn algemeenheid in strafzaken culturele

19 M.L. Haimé, Culturele diversiteit en rechterlijke macht, in: E. Bauw e.a. (red.), Mijnheer de voorzitter. Liber amicorum A.H. van Delden, Den Haag: Boom Juridische uitgevers 2007, p. 137.

20 Veelzeggend is dat advocaten soms aarzelen of ze er goed aan doen om de culturele factor in te brengen.

21 Zie ook Hof Arnhem 5 september 2002, LJN AE733: 'Zo de culturele achtergrond al strafverminderend zou kunnen werken [curs. HDW], wordt dit tenietgedaan door het belang van de generaal preventieve werking van de straf.' Dat is onbevredigend. De achtergrond werkt strafverminderend of niet. Ceteris paribus moet in het eerste geval de straf lager zijn dan in het tweede geval. 
achtergronden tot straffeloosheid, strafverhoging of strafvermindering zouden moeten leiden, maar of en zo ja, op welke wijze dergelijke achtergronden in het concrete geval van een individuele strafzaak de verdachte hebben gevormd c.q. beïnvloed. Dat is onderdeel van het in elke strafzaak uit te voeren onderzoek naar de persoon van de verdachte." 22

De praktijk - in de vorm van de strafmotivering in concrete zaken laat zien dat culturele factoren zeer verschillend in de straftoemeting kunnen doorwerken. ${ }^{23}$ Indien de culturele achtergrond erin bestaat dat er een druk op de dader is uitgeoefend om het delict te plegen en die druk de wilsvrijheid van de dader heeft aangetast, zij het niet voldoende om psychische overmacht aan te nemen, houdt de rechter daarmee in het algemeen rekening in voor de verdachte gunstige zin. Zo kan een door anderen uitgeoefende druk om het delict te plegen strafverminderend werken. ${ }^{24}$ Heel duidelijk is dat in het geval een minderjarige door zijn ouder tot het plegen van het delict wordt aangezet. ${ }^{25}$ Dat lijkt onproblematisch en is ook niet bijzonder. Een door anderen uitgeoefende druk kan in het algemeen maken dat de mate van schuld minder is, of die druk cultuurbepaald is of niet. ${ }^{26}$ Ook zonder beïnvloeding van derden kan de dader zich onder druk gezet voelen door het culturele verwachtingspatroon. De Nederlandse rechter lijkt daarmee ook rekening te houden. Als cultuur inderdaad dit effect op mensen kan hebben, is daar niets op tegen - dat geldt voor elke 'achtergrond', voor elke 'bron' van druk. Vanzelfsprekend is van belang na te gaan óf de culturele achtergrond deze rol heeft gespeeld. Het plegen van het delict kan immers ook het gevolg zijn geweest van gevoelens die met die cultuur niets te maken hebben (gekwetstheid, jaloezie, haat) en die ook bij de niet-culturele dader kunnen spelen.

Het enkele gegeven dat de dader het delict heeft gepleegd omdat dit 'paste' in zijn cultuur, wordt doorgaans niet gezien als een grond voor strafvermindering: "dat verdachte kennelijk in de mening verkeerde dat de moord op zijn tante noodzakelijk was om de eer van de familie te redden (...) doet

22 Rechtbank 's-Hertogenbosch 13 februari 2001, LJN AA9954.

23 Zie ook J. ten Voorde, Het zwaarder straffen bij culturele delicten. Feit of fictie, Proces 2004, p. 124 e.v.

24 Zie bijv. Hof Leeuwarden 19 juni 2000, LJN AD8362.

25 Rechtbank 's-Hertogenbosch 13 februari 2001, LJN AA9954.

26 Ter vergelijking: ongunstige sociale omstandigheden kunnen een strafverlagend effect hebben. De ongunstige omstandigheden kunnen een culturele achtergrond hebben. De culturele achtergrond als zodanig heeft dan geen strafverlagend effect. 
aan de strafwaardigheid van die moord niets af." ${ }^{27}$ Wanneer de culturele achtergrond van het plegen van het delict uit niets meer bestaat dan het 'kale' motief, zonder dat dit gepaard gaat met enige druk die de wilsvrijheid van de dader aantast (volgens de rechter), lijkt er inderdaad geen reden voor strafvermindering. Nogal eens kent de Nederlandse rechter aan het eerwraakmotief juist een strafverzwarende werking toe. Dat gebeurt om verschillende redenen. ${ }^{28}$ Een daarvan is het aspect van eigenrichting: "Iedere vorm van eigenrichting en daarmee ook conflicten als de onderhavige bloedwraak zijn binnen de Nederlandse samenleving volstrekt onacceptabel." ${ }^{29}$ De term eigenrichting is in dit verband wellicht misleidend, althans voor zover deze toch een zeker recht aan de kant van de dader suggereert - hij had dat alleen niet in eigen hand mogen nemen. Maar niet de eigenrichting als zodanig maakt het eerwraakdelict zo ernstig; het is vooral de enorme wanverhouding tussen aanleiding (eerkrenking) en daad (moord of geweld). Iets daarvan komt tot uiting in een andere soort motivering: "Het motief van deze moord is gelegen in het feit dat het slachtoffer de eer van haar familie geschonden had; zij was ongehuwd zwanger geraakt van een man die geen moslim is. Moord is een van de ernstigste delicten uit het Wetboek van Strafrecht. (...) $\mathrm{Nu}$ in het onderhavige geval het motief van de moord is gelegen in eerwraak, impliceert dit misdrijf tevens een miskenning van het (in ieder geval in Nederland bestaande) recht van de vrouw om haar leven in te richten op de wijze die zij zelf verkiest. ${ }^{30}$ Aanleiding voor de moord is het verrichten van een gedraging waartoe juist het volste recht bestaat en dat maakt de 'eigenrichting' des te ernstiger. ${ }^{31}$

Tenslotte leiden overwegingen van preventie soms tot een zware bestraffing: "Voorts dient bij de straftoemeting het generaal-preventieve element een rol te spelen, als signaal aan de samenleving dat 'namus' kwesties in geen enkel geval in Nederland met moord en doodslag dienen te

27 Rechtbank Haarlem 9 mei 2001, LJN AB1503. Vgl. ook Rechtbank Dordrecht 30 december 1999, LJN: AA4019.

28 Zie ook Ten Voorde (noot 2), p. 62 e.v. en p. 293 e.v.

29 Hof Arnhem 12 juni 2002, LJN AE4029; vgl. ook Rechtbank Middelburg 15 oktober 2003, LJN AL9045.

30 Rechtbank 11 november 2005, LJN AU5991; zie ook Rechtbank Alkmaar 4 maart 2008, LJN BC5712; zie ook Hof 's-Gravenhage 23 juni 2005, LJN AU0180.

31 Dat is overigens geen argument om van het eerwraakmotief toch een wettelijke strafverzwaringsgrond te maken, zoals wel eens wordt bepleit. Zó bijzonder is dit motief niet in vergelijking met sommige andere verwerpelijke motieven, zoals puur winstbejag. 
worden opgelost." 32 Indien de dader het (volstrekt) ongeoorloofde van zijn handelen niet inziet en overtuigd blijft van de juistheid ervan, kan om reden van speciale preventie een zware straf geïndiceerd zijn: "Voorts acht de rechtbank van belang dat verdachte nog immer niet lijkt in te zien dat zijn handelen verkeerd is geweest, gelet op zijn verklaring ter terechtzitting dat de kans op recidive niet aanwezig is omdat zijn dochter heeft ingezien dat het verkeerd is wat zij heeft gedaan [cursivering HDW]. ${ }^{, 33}$ De rechter dient zich er wel van te vergewissen dat de dader hier niet enkel een houding aanneemt - een houding die zelf ook weer cultuurbepaald kan zijn (niet verloochenen van de eigen cultuur).

\section{Slot}

Een korte opmerking ter afsluiting. De rol van cultuur komt in strafzaken vooral aan de orde bij de beoordeling van een beroep op psychische overmacht en bij de straftoemeting. De vraag of 'cultuur' een reden is voor strafuitsluiting (of juist niet) dan wel voor strafvermindering (of juist niet) is geen zinvolle vraag. Dat is niet omdat de invloed van iemands cultuur op het plegen van een delict geen relevante omstandigheid is. Het punt is dat die invloed allerlei vormen kan aannemen. Dat vraagt om een genuanceerde benadering ${ }^{34}$ van het fenomeen culturele delicten.

32 Rechtbank Haarlem 9 mei 2001, LJN AB1503; zie ook Hof Arnhem 5 september 2002, LJN AE7333; Hof 's-Gravenhage 23 juni 2005, LJN AU0180; Hof Arnhem 6 juli 2005, LJN AT8835.

33 Rechtbank Alkmaar 4 maart 2008, LJN BC5712. Vgl. ook Rechtbank Dordrecht 21 oktober 2003, LJN AM2493.

$34 \mathrm{Zie}$ in dit verband de sprekende titel van het proefschrift van Wiersinga: 'Nuance in benadering' (noot 2). 